\title{
Impact and Shock of Network Economy on Business Administration
}

\author{
Jiangfan Ma \\ Shenzhen Zhongtaida Group, Shenzhen, 518031, China
}

Keywords: Network economy, Business administration, Impact, Shock, Strategies

\begin{abstract}
The rapid development of the network economy has brought no small impact and impact to the administrative departments for Industry and commerce. This paper analyzes the influence of network economy on the industry and commerce administration, pointed out that the development of the network economy can improve the administrative department of industry and commerce work efficiency, reduce management costs, to provide the quality of the staff, to collect information more convenient, establish the good atmosphere of the industry, with the development of network economy analysis also brought no small impact to the traditional business the administrative management, finally puts forward the industrial and commercial administrative departments should change their concepts, to accelerate its pace of development and improve the legal system to adapt to the requirements of the development of network economy.
\end{abstract}

\section{Introduction}

The network economy has been developing well in recent years, which is based on the development of Internet technology. The most important feature of the network economy is its information characteristics. It is a new economic form based on information characteristics. The network economy is dominated by the information industry and service industry. The network economy is also called "information economy" and "new economy" because of its characteristics in the economic circles. With the development of economic globalization and the rapid development of the Internet, the era of big data is obviously coming for a long time, the network economy came into being, and it play a more prominent in the economic field, and had a certain impact on the existing economic model, but also because of the current economic model had no small change. The administration of industry and commerce plays a macro regulatory role in the development of market economy, which requires that it play a role in maintaining the order of market economy in the development of market economy. Only in this way, the market economy system is healthy. The rise of the network economy requires the administrative departments for Industry and commerce to comply with the requirements of the development of the times and promote the development of the network economy and even the whole economy.

\section{Impact of Network Economy on Business Administration}

\subsection{Improve Work Efficiency}

There are many processes in the traditional administration of industry and commerce. Most of the people involved in the administration of industry and Commerce show that the process is tedious and the work efficiency is low. Along with the development of network technology, it is widely in various units of application, network technology has changed the traditional way of information, the application of network technology information transmission efficiency has been improved, in industrial and commercial administration can avoid the tedious process, greatly improving the work efficiency of administration of industry and commerce. 


\subsection{Reduce Management Cost}

The network economy has effectively improved the efficiency of the administration of industry and commerce, optimized the traditional way of work, reduced the working time, and made the work close to the central procedure, avoiding unnecessary auxiliary work. The reduction of unnecessary workflow reduces the amount of staffing in the work process and reduces the management cost. At the same time, unnecessary resource consumption is also reduced due to the application of network technology. Information transmission is faster, management work efficiency is improved, and the necessary flow costs in management work are also reduced.

\subsection{Enhance Employee’s Quality}

With the continuous development of network technology and technology, the workflow of industrial and commercial administration has been changed. The tedious process of traditional work in industrial and commercial administration must be improved and optimized, so that the administration of industry and Commerce will conform to the trend of the times. At the same time, the application of new technology requires the staff to have the corresponding quality and the requirements for the staff. The staff must master the application of network technology while knowing professional knowledge, and flexibly apply network technology in their work. In the past, it is beneficial to improve the quality of employees, and then improve the level of industrial and commercial administration system, to ensure the quality of work and to improve the efficiency of work.

\subsection{It is more Convenient to Collect Information}

The application of network technology makes information collection, sorting and analysis work not limited to time, nor is it limited to work place. Information collection in business administration is faster and more convenient. Network technology enables the industry and commerce administration department to understand the market situation in time, collect information easily, manage and supervise relevant departments, and lay a solid foundation for the smooth development of business management.

\subsection{Form Good Atmosphere}

The application of network makes the work flow does not limit the time and place restrictions, enterprises need to provide relevant information to the administrative department for Industry and Commerce in the project application, submit the data of traditional working process is very complicated, and the network technology can provide a convenient channel for the submission of information, to avoid the enterprise due to cumbersome procedures and staff speech conflict. The staff working environment will be facing the computer, to avoid the social atmosphere of unhealthy tendencies, "go" and "favor" in the application of network technology in the unwholesome tendencies can be avoided. Under the network economy, the administration of administrative and commercial administration can effectively guide the related industries to set up good atmosphere, which is beneficial to the effective work of all sectors of the society.

\section{Shock of Network Economy on Business Administration}

\subsection{Market Access, Registration and Registration}

The network era the rise of many new industries, the business management department is facing a lot of problems in the relevant registration, also put forward the new request to the administrative department for Industry and commerce, such as registration and qualification assessment requires the administrative department for Industry and Commerce in a timely manner to understand the specific situation of new industries, new industries and emerging industries of derivatives the related decision and application and the corresponding management work flow. The administrative department for Industry and Commerce in the face of new business registration application to understand under what 
conditions the enterprise can be established, as some information technology enterprises on how to define the equipment, personnel, and other aspects of the site is the administrative department of industry and commerce to further study the problem. In the process of work, people will continue to use traditional working mode, which will make work efficiency lower. The operation of the whole system is contrary to the requirements of the times, which is not conducive to the work of industry and commerce administration department, nor to the development of social economy.

\subsection{Market Behavior Norms}

In the new era, people adopt a new way of life and work, and the social activities are diversified. The application of network technology in intelligent mobile phone is developed and the rapid development of e-commerce, such as bisazenes achieve advertising work, scientific researchers to study and research through online resources, hospital appointment registration work carried out by WeChat medical, education and counseling agencies in the live webcast, sharing of educational resources are the new situation in the new era of network technology application. The diversification of the situation makes the administrative staff of industry and Commerce shoulder new responsibilities. The current market has many characteristics of virtual enterprise, virtual enterprise is simple and flexible to its rapid development in the market, the virtual enterprise distributed, expanding, sharing, and low-cost characteristics also make the market behavior is rapid, diversity, which makes the industry and commerce administration work is more cumbersome, difficult work. The virtual enterprise is mainly based on the development of information technology, and how to effectively carry out the administration of industry and commerce, and regulate the market behavior is clearly related departments need further discussion. Under the network economy the fierce competition between enterprises, how to carry out the work of the administrative department of industry and Commerce in this competitive environment, facing the guarantee in fairness and justice is clearly relevant departments, relevant departments are also important guarantee to properly solve this problem to work smoothly. The online advertising industry is developing rapidly. How to regulate the market behavior of the online advertising industry under such a background is an important guarantee for the operation of the market standard. The rush for Internet domain names is also facing a great impact on the work of industry and commerce administration departments. The application of scientific and reasonable working mode in relevant departments to protect legitimate intellectual property rights is clearly the only way for the development of network economy.

\subsection{Economic Management Concept}

Because of its particularity, the industry and commerce administration departments must play a role of public relations in the development of market economy, which is also the "responsibility" and "right" granted by the government to the administrative departments for business administration. The administrative department of industry and commerce should be based on the requirements of the development of market economy, combined with their own development requirements, from equipment to arm themselves, make their own system to optimize, and improve work efficiency; at the same time to abandon the traditional backward management concept but also the relevant departments must do, only set up the advanced management concept to make the industry and commerce administration work smoothly the long-term development of the market economy to be healthy. To sum up, under the network economy, the administrative departments of industry and commerce are facing a great impact on management concepts, requiring them to take corresponding measures to comply with the requirements of the times.

\subsection{Quality of Personnel}

Network technology is injecting fresh blood. Under the network economy, people in all fields are required to apply network technology to reduce work pressure and improve work efficiency, especially for Industry and commerce administration department. In China, there is an aging phenomenon in the staffing of industrial and commercial administration departments. The employees are not very good at grasping the new network technology. Obviously, when applying network 
technology, they feel the pressure is huge, even some people are not competent. However, under the network economy, people are required to master professional knowledge and grasp the application of network technology. This makes our industry and commerce management staff face the impact of quality requirements, requiring the staff to have high comprehensive quality.

\subsection{Laws and Regulations}

Since the founding of PRC, the law has been constantly improving and optimizing, but the existing legal system is not very standardized for the development of enterprises under the network economy. There are often some enterprises doing some illegal activities with "legal loopholes". As the administrative department, the law of industry and commerce is naturally the law of our country, but the existing law is hard to adapt to the rapid development of the network economy system, because the legal system is also facing a new round of impact under the development of the network economy.

\section{Measures of Effective Business Administration Based on Rapid Development of Network Economy}

\subsection{Transform Ideas}

The industry and commerce administration department should comply with the development of the times, respond to the requirements of the development of the network economy, effectively serve the network economy, and enable the new market economic order to be established under its scientific management and supervision. This requires that the administrative department of industry and Commerce transfer from traditional management concept to new management concept. Under the new management concept, the Department should attach importance to personnel training, intensify personnel training under the correct guidance of new ideas, improve the overall quality of employees, and strengthen the construction of working system. We should strictly control network access licensing, resolutely put an end to the operation of non-standard things, and coordinate the relationship between daily registration and network registration, so that they can cooperate with each other. The application of modern management means to reduce the use of traditional paper registration mode in management work can not only improve work efficiency, but also make the working process truly realize "low carbon" way. To state law based on high-tech industry access conditions and evaluation, as far as possible to provide a convenient channel for the scientific and reasonable, and actively promote the high-tech industry development, and encourage social capital into new industries, conducive to the overall development of the national economy.

\subsection{Accelerate Development Pace}

High technology has been developing rapidly in the development of network economy. High tech industry naturally regards technology as its foothold. However, there are many influencing factors in the operation of market economy. Compared with traditional industries, the industry and commerce administration must not follow the existing economic development requirements if they continue to use the traditional mode when dealing with the first half of the high-tech industry. Based on the above situation, managers are required to have knowledge of operation and management in high-tech industry, and then analyze the illegality of some illegal elements more conveniently, and reduce unnecessary losses for all social groups. In the process of work, to give the development of the network economy, the business management staff must apply the technology that corresponds with the times. For the employees in the system, the relevant leaders should regularly organize the ability assessment, so that employees can continuously improve themselves in the long-term work, and then improve the strength of the business management team to make the management work efficiently and smoothly. Only by keeping up with the improvement of the quality of employees can the development of the market economy be more harmonious and promote the development of China's network economy and the whole economy. 


\subsection{Perfect Legal System}

The network economy is a new look in the economic development. Any new thing will face many problems. The effective solution of these problems is the important guarantee for the long-term healthy development of new things. So is the network economy. There are many problems in the development of network economy. It is worth studying and discussing by relevant enterprises and departments. Only by grasping the law of economic development and proceeding from the phenomenon of economic development, can we make the network economy develop in a long term and sustainable way. Mastering the law of economic development and basing on the current situation of economic development, we can formulate a legal system that is in line with the development of the existing network economy. The administrative department for Industry and commerce can carry out the work smoothly and play a good role in monitoring the development of the market economy. China is a country under the rule of law, and the rule of law is the prerequisite for all social activities. Relevant departments should speed up the formulation of corresponding legal system for the development of network economy, so that relevant administrative departments in the development of network economy have laws to follow, so that we must strictly enforce the law, standardize the development of market economy, and reduce the occurrence of market failure. The improvement of the legal system should be based on the overall development of the market economy, effectively avoid the phenomenon of monopolistic market, and enable the industry and Commerce Administration's macro control function to play effectively under the support of the perfect legal system.

\section{Conclusion}

The development of network economy makes the administration of industry and commerce more convenient and efficient. Because of the great changes of its market structure, the administration of industry and commerce is facing many challenges and challenges. This requires relevant departments to take appropriate measures to ensure the smooth progress of the administration of industry and Commerce and effectively promote the development of the network economy.

\section{References}

[1] He Zhe. The Network Economy: Beyond Planning and Market [J]. Comparative Economic \& Social Systems, 2016(2): 163-173.

[2] Wu Yuan, Yu Huawen. Reflections on Network Economy's Impacton Industrial and Commercial Administration [J]. Journal of Ningbo University (Liberal Arts Edition), 2006, 19(2): 91-93+121.

[3] Cai Hongbo. Do the Fittest Survive in the Network Economy? - Analysis on Critical Mass and Butterfly- effect in New Product Network Industrial Economics Research [J]. 2012(3): 41-49+94.

[4] Cheng Liru. A Study on Innovation Mechanism of Enterprise Value Network from the Perspective of the Internet Economy China Industrial Economics [J]. 2013(9): 82-94. 